\title{
Potenzsymbol oder Naturpullover?
}

\author{
BVB-Trainer Klopp macht es vor: Haarverpflanzungen \\ bei Männern sind in - allerdings sprechen nur \\ wenige darüber. Wenn Sie wissen möchten, was \\ sonst noch beim Thema Haare en vogue ist, dann le- \\ sen Sie unseren Trendbericht.
}

Jürgen Klopp hat sich seine Geheimratsecken per Haarverpflanzung aufpolstern lassen - und findet das Ergebnis "ganz cool“. Tatsächlich legen sich Männer am Häufigsten wegen ihrer Kopfhaut unters Messer. „Wenn Männer Haare verlieren, ist das für sie ein Zeichen für nachlassende Manneskraft", sagt Frank Neidel, Präsident des Verbands Deutscher Haarchirurgen. Etwa 85 \% seiner Patienten seien Männer. „Männer beginnen langsam sich zu outen", meint er mit Blick auf die ermunternden Bekenntnisse von Männern wie Silvio Berlusconi, Wayne Rooney und zuletzt Jürgen Klopp. Das mache das Thema en vogue. Heutzutage sagten sich Betroffene daher vor allem: „Ich fühle mich jünger als ich aussehe“, und wollten dieses Missverhältnis beheben.

\section{Comeback der Perücke?}

Auch der gute alte „Fiffi“ kommt in der Haarmode zurück. Zumindest wenn man Peter Volk glaubt, dem Vorsitzenden des Bundesverbands der Zweithaarspezialisten. Die früher als „Toupet“ verschmähte Kopfbedeckung erfreue sich seit gut zehn Jahren wieder größerer Beliebtheit. „In den 70er-Jahren mit den vollen Haaren war der Haarersatz in Mode. Durch die Sportphase ab den 80ern trugen die Männer eher kurzes Haar", sagt er.

Durch die Bonding-Technik, die eine verlässliche und dichte Verklebung seit gut zehn Jahren möglich mache, sei das oft persiflierte Stück vor allem bei Männern wieder gefragt.

Die Perücke als weibliche Zweitfrisur, die Jackie Kennedy mit ihrem schwarzen Bob in den 60er- und 70er-Jahren zum Trend machte, gilt dem Experten zufolge aber mittlerweile als ausgestorben.
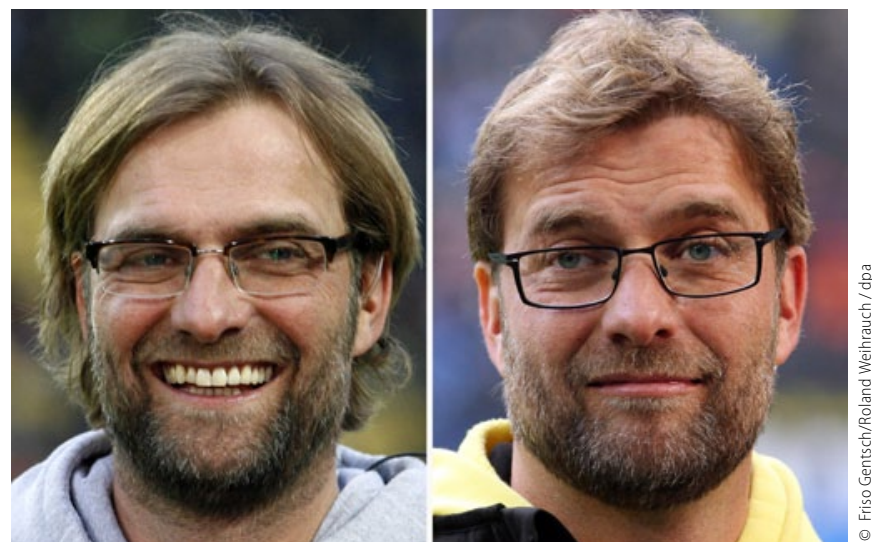

Haarvergleich: BVB-Trainer Jürgen Klopp vor und nach der Haartransplantation.

\section{Trend zum Schamhaar}

Was unterscheidet die Geschlechter im Umgang mit der Haarpracht? Die Ästhetik von Film-, Musik- und Sportstars scheint es dem Mann von heute schon fast nicht mehr zu erlauben, im sogenannten „Naturpullover“ auf Brust und Rücken im Freibad zu erscheinen. Glattrasiert bis unter die Achseln - so präsentieren sich in Videoclips Musikstars und in den Fußballstadien jubelnde Torschützen. Selbst das maskuline Aushängeschild James Bond wurde vom brustbehaarten Sean Connery zum glatten Daniel Craig.

Bei Frauen sind nach wie vor die Achselhaare so tabu wie das behaarte Bein. Und wenn es ans Eingemachte geht, dann sehen Studien insbesondere bei Jüngeren beiderlei Geschlechts die Unlust am Haar: Frei zugängliche Pornografie und Gruppenzwang sorgen demnach für blanke Intimzonen. Doch auch diese Zone unterliegt Moden, und so verkünden erste Stimmen bereits wieder den Trend zum Schamhaar.

\section{Hier steht eine Anzeige.}

